\title{
Imatinib-induced hepatitis treated by corticosteroids in a patient with metastatic gastrointestinal stromal tumor
}

\author{
Min Kyu Kang ${ }^{1}$, Heon Ju Lee ${ }^{1}$, Joon Hyuk Choi ${ }^{2}$ \\ ${ }^{1}$ Department of Internal Medicine, Yeungnam University College of Medicine, Daegu, Korea \\ ${ }^{2}$ Department of Pathology, Yeungnam University College of Medicine, Daegu, Korea
}

Received: December 4, 2018

Revised: January 14, 2019

Accepted: January 16, 2019

Corresponding author:

Min Kyu Kang

Department of Internal Medicine,

Yeungnam University College of

Medicine, 170, Hyeonchungno,

Nam-gu, Daegu 42415, Korea

Tel: +82-53-620-3316

Fax: +82-53-654-8386

E-mail:kmggood111@naver.com
Imatinib mesylate is currently used as the first-line treatment for metastatic gastrointestinal stromal tumors (GISTs). Imatinib-induced hepatotoxicity in patients with GIST is very rare. Its features vary from subclinical elevation of serum aminotransferase to clinically apparent acute hepatitis, which is associated with immunologic reactions. Imatinib-induced hepatotoxicity with autoimmune-like features can be treated by the discontinuation of imatinib mesylate and the administration of oral steroids. Here, we report a case of late-onset imatinib-induced hepatitis with autoimmune-like features in a patient with metastatic GIST, which was improved by oral corticosteroids.

Keywords: Corticosteroids; Drug-induced liver injury; Gastrointestinal stromal tumors; Imatinib mesylate

\section{Introduction}

Imatinib mesylate is a selective inhibitor of the BCR-ABL tyrosine kinase, which is widely used for the treatment of chronic myelogenous leukemia, Philadelphia chromosome-positive acute lymphoblastic leukemia, and C-kit (CD 117)-positive advanced metastatic gastrointestinal stromal tumor (GIST) [1,2]. Imatinibinduced hepatotoxicity has been reported in less than $2.5 \%$ of patients with GIST [3]. Although the mechanism of imatinibinduced hepatotoxicity is unclear, it is thought to be an idiosyncratic reaction to the drug [3]. Most patients present with mild elevation of aminotransferase during first 2-3 months of imatinib treatment [4]. In general, imatinib-induced hepatotoxicity is improved within 4 weeks of drug discontinuation $[3,4]$. However, in cases of liver enzyme deterioration after the discontinuation of imatinib, corticosteroids can be used $[2,5]$. Herein, we have reported a case of late-onset imatinib-induced hepatitis treated with corticosteroids in a patient with metastatic GIST.

\section{Case}

A 55-year-old man was referred to our department with deterioration of liver function. He had undergone segmental resection of the small bowel and peritonectomy for metastatic GIST, which had caused massive hematochezia 10 months ago. The tumor had spread into the omentum and the pelvic cavity with scattered nodules. The pathology results indicated the coexpression of CD113 and CD34 spindle cells, with a mitotic index of 4 per 50 high-power fields. After the surgery, palliative chemotherapy with imatinib mesylate $400 \mathrm{mg}$ daily was initiated.

After 10 months of imatinib therapy, the patient was referred to our department owing to elevated aminotransferase level without any specific symptoms for several months. He denied any causal alcohol consumption or medication. His physical examination was normal. The laboratory tests revealed the following values: white blood cell count, $4,770 / \mu \mathrm{L}$; eosinophil count, $467 / \mu \mathrm{L}$ (range, $<500 / \mu \mathrm{L}$ ); hemoglobin, $13.8 \mathrm{~g} / \mu \mathrm{L}$; 
platelet count, $184 \mathrm{~K} / \mu \mathrm{L}$; total protein, $6.34 \mathrm{~g} / \mathrm{dL}$; albumin, $\mathrm{g} / \mathrm{dL}$, total bilirubin (TB), $1.59 \mathrm{mg} / \mathrm{dL}$; direct bilirubin, 0.31 $\mathrm{mg} / \mathrm{dL}$; aspartate aminotransferase (AST), $239 \mathrm{IU} / \mathrm{L}$; alanine aminotransferase (ALT), 393 IU/L; alkaline phosphatase, 194 IU/ L (range, 30-120 IU/L); gamma glutamyl transferase, 52 IU/L (range, <50 IU/L); blood urea nitrogen, $12 \mathrm{mg} / \mathrm{dL}$; creatinine, 1 $\mathrm{mg} / \mathrm{dL}$; and international normalized ratio, 1.06. Serologic markers for viral hepatitis, including hepatitis A virus, hepatitis B virus, and hepatitis $C$ virus, were negative. There was no evidence of acute viral infection, and tests for Epstein-Barr virus, cytomegalovirus, and herpes virus were not performed. To exclude autoimmune hepatitis (AIH) and primary biliary cholangitis, additional serologic tests were conducted, including anti-nuclear antibody, anti-smooth muscle antibody, anti-mitochondria antibody, immunoglobulin G (IgG), IgA, IgM, anti-neutrophil cytoplasmic antibody, and anti-liver kidney microsomal type 1 antibody, and all results were within the normal ranges. Computed tomography (CT) of the abdomen revealed no evidence of recurrence of GIST compared with previous CT scan (Fig. 1). After immediate discontinuation of imatinib therapy, supportive treatment, including $300 \mathrm{mg}$ ursodeoxycholic acid daily and nutritional support with high calorie and protein, was initiated. Despite 3 weeks of supportive treatment, serum levels of AST, ALT, and TB increased up to $255 \mathrm{IU} / \mathrm{L}, 470$ $\mathrm{IU} / \mathrm{L}$, and $2.07 \mathrm{mg} / \mathrm{dL}$, respectively. The $\mathrm{R}$ factor for liver injury was 7.6, which was equivalent to hepatocellular liver injury. The Roussel Uclaf Causality Assessment Method score was 6, which
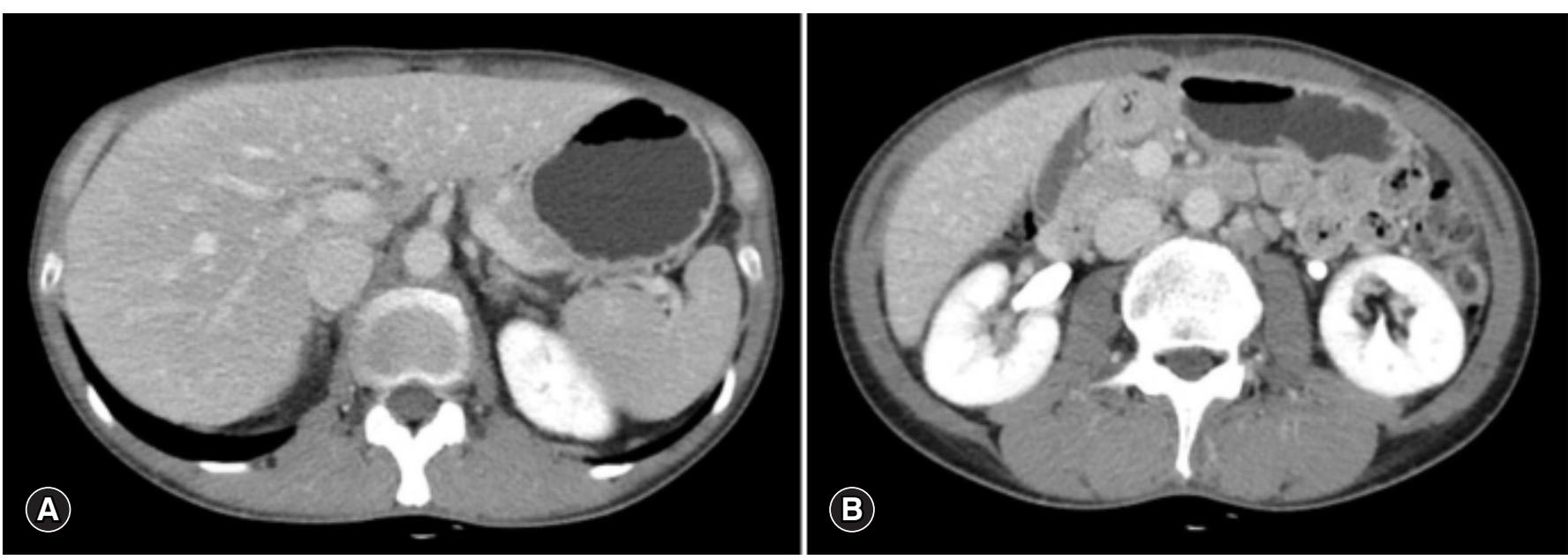

Fig. 1. Abdominal computed tomography reveals no evidence of recurrence of GIST from upper abdomen (A) to lower abdomen (B) after segmental resection of small bowel and peritonectomy for metastatic GIST. GIST, gastrointestinal stromal tumor.
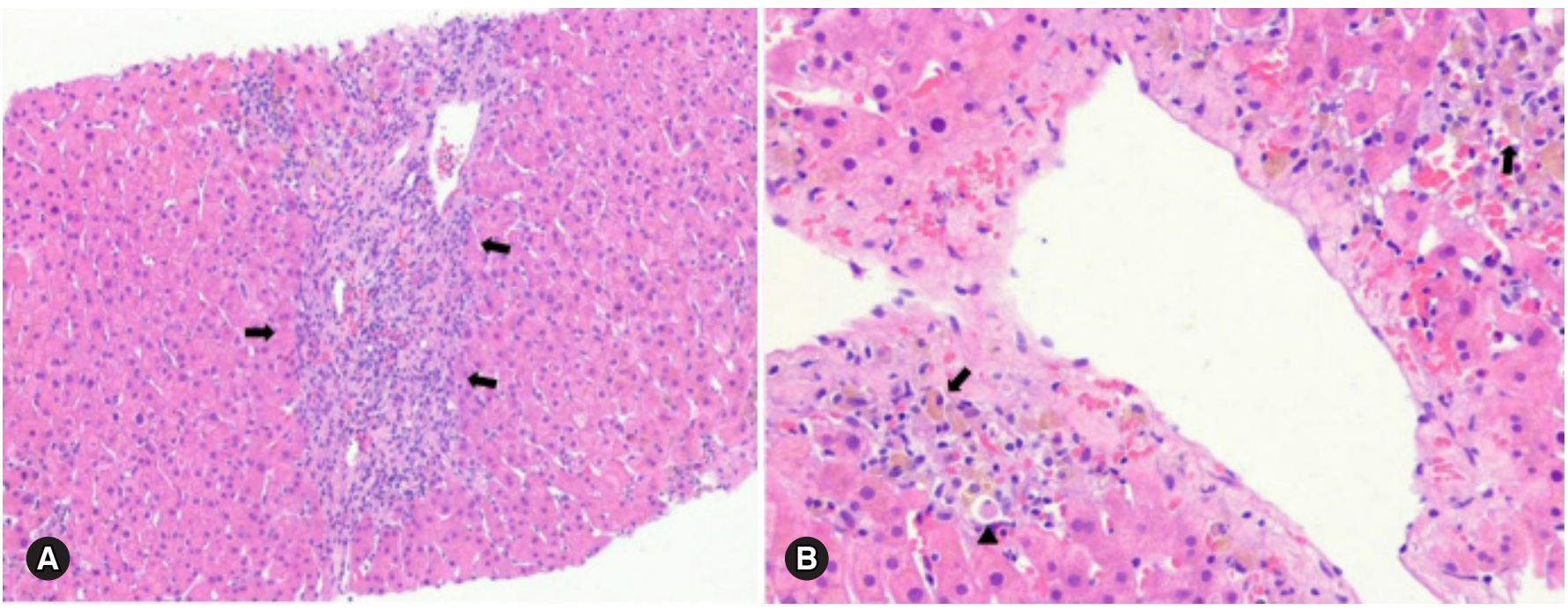

Fig. 2. Histological findings of the liver. (A) There is interface hepatitis with inflammatory cells infiltrations of lymphocytes and plasma cells (arrows) in portal and periportal area (hematoxylin and eosin stain, $\times 100$ ). (B) The centrilobular necrosis is present, with golden-brown colored ceroid pigment-laden Kupffer cells (arrows) and shrunken, eosinophilic apoptotic hepatocytes (arrow head) (hematoxylin and eosin stain, $\times 200$ ). 
indicated that drug-induced liver injury (DILI) was probable.

To exclude the possibility of DILI, a percutaneous liver biopsy guided by ultrasound was performed. The pathologic findings revealed centrilobular necrosis and mild interface hepatitis, consistent with DILI with suspicious autoimmune-like features (Fig. 2). The Revised Original Score for AIH for pretreatment was 10 , which indicated that AIH was probable.

As we could not completely rule out the relationship with autoimmunity, we decided to administer steroids. The patient was treated with $30 \mathrm{mg}$ prednisolone daily. After 2 weeks, his laboratory test results were improved: AST, 40 IU/L; ALT, 132 IU/L; and TB, $0.87 \mathrm{mg} / \mathrm{dL}$. Subsequently, prednisolone was tapered, to $15 \mathrm{mg}$ daily for 2 weeks. After 4 weeks, his laboratory test results were normal: AST, $29 \mathrm{IU} / \mathrm{L}$; ALT, $40 \mathrm{IU} / \mathrm{L}$; and TB, $0.91 \mathrm{mg} / \mathrm{dL}$ (Fig. 3). A reduced dose of imatinib mesylate (300 mg daily) was restarted without further deterioration of liver function over a follow-up period of 4 months. In addition, Revised Original Score for AIH for post-treatment was 12, which indicated that $\mathrm{AIH}$ was probable.

\section{Discussion}

The clinical manifestations of imatinib-induced hepatotoxicity are varied in patients with GIST (Table 1). In our patient, grade 3

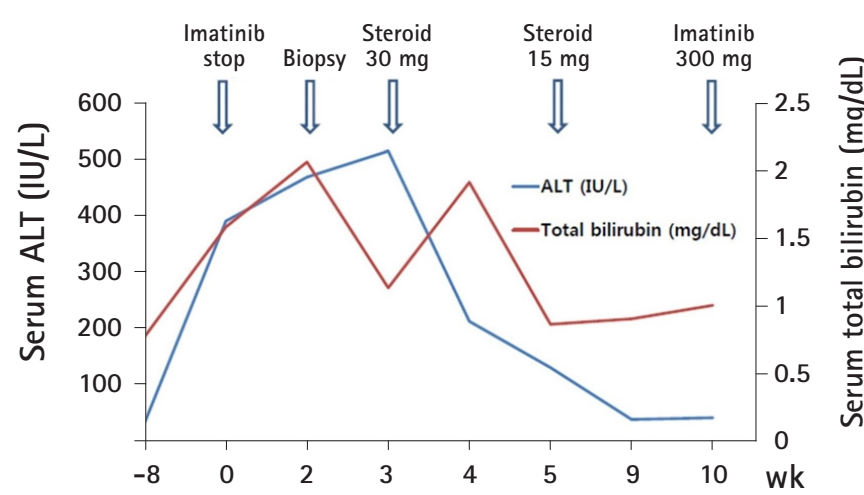

Fig. 3. Clinical course of the patient. ALT, alanine aminotransferase.
ALT elevation first occurred 10 months after the administration of imatinib. The onset period of imatinib-induced hepatotoxicity is reported to be between 11 days and 13 months [4,6]. Serum levels of aminotransferase are usually elevated within the first 2-3 months after imatinib administration, and are improved within 4 weeks after discontinuation $[4,7]$. In addition, the clinical features of imatinib-induced hepatotoxicity in patients with GIST range from transient elevation of serum aminotransferase to acute liver injury, which may cause cirrhosis $[2,4,8]$.

Although the pathogenic mechanisms of imatinib-induced hepatotoxicity are not fully understood, they may be associated with idiosyncratic hypersensitivity reactions to the drug in susceptible patients [9]. The drug metabolism pathway in the liver is divided into four phases, phase 0 to phase $3[10,11]$. In phase 0 , the drug is transported from the blood to the liver via the carriermediated uptake system, including soluble carrier (SLC21/ SLCO) [11]. The drug transported into the liver is metabolized in phase 1 (oxidation via the enzyme cytochrome P [CYP] 450) and phase 2 (conjugation via mainly UDP-glucuronosyltransferase) [10]. In phase 3, conjugated metabolites are excreted into the cells by active transporter pumps using multidrug resistance-associated protein 2 and multidrug resistance protein 1/P-glycoprotein [11].

Imatinib mesylate is metabolized mainly by CYP450 enzymes, such as CYP3A4, CYP2C9, and CYP2D [2]. Drugs and foods that interfere with CYP450 enzymes, such as erythromycin, roxithromycin, itraconazole, and grapefruit juice, may elevate the serum concentration of imatinib metabolites, which may cause hepatotoxicity [2]. The pregnane $\mathrm{X}$ receptor and constitutive androstane receptor play an important role in drug interactions, acting as transcriptional regulators of CYP 450 [12].

In addition, the histopathologic findings of imatinibinduced hepatitis include diverse manifestations, including periportal inflammation, focal necrotic hepatocytes with mixed lymphocytes, neutrophil infiltration, extensive centrilobular hepatic necrosis, and severe cytolytic acute hepatitis [1,2].

Most cases of hepatotoxicity are resolved by reduction or discontinuation of the medication. In one case, steroids reversed

Table 1. Imatinib-induced hepatotoxicity in patients with gastrointestinal stromal tumor

\begin{tabular}{lcccccc}
\hline Reference & Age/sex & Dose $(\mathrm{mg})$ & $\begin{array}{c}\text { Time to } \\
\text { hepatotoxicity }\end{array}$ & $\begin{array}{c}\text { Type of } \\
\text { hepatotoxicity }\end{array}$ & $\begin{array}{c}\text { Steroid initial dose } \\
\text { (mg/day) }\end{array}$ & Rechallenge \\
\hline Pariente et al. [1] & $71 / \mathrm{F}$ & 400 then 300 & $7 \mathrm{wk}$ & Cytolytic hepatitis & No & Yes \\
Tonyali et al. [2] & $53 / \mathrm{F}$ & 400 & $10 \mathrm{wk}$ & Acute liver failure & PD 40 & Sunitinib \\
Seidal et al. [3] & $49 / \mathrm{M}$ & 400 & $6 \mathrm{mon}$ & Liver cirrhosis & No & No \\
Yachoui [4] & $46 / \mathrm{F}$ & 400 & $11 \mathrm{~d}$ & Acute hepatitis & No & No \\
Saif et al. [14] & $65 / \mathrm{M}$ & 400 then 200 & $2 \mathrm{mon}$ & Gilbert's syndrome & No & No \\
Our case & $55 / \mathrm{M}$ & 400 then 300 & $10 \mathrm{mon}$ & Acute hepatitis & PD 30 & Yes \\
\hline
\end{tabular}

$\mathrm{PD}$, prednisolone. 
imatinib-induced immune hepatitis, as characterized by persistent elevations of autoantibodies, including anti-nuclear antibody and double-strand antibodies, after discontinuation of imatinib for 2 weeks [6]. In addition, despite no clear immunologic features, imatinib-induced hepatotoxicity was improved after the administration of oral steroids [2,5]. In our case, despite discontinuation of imatinib for 3 weeks, laboratory results were exacerbated, with elevations in ALT (grade 4) and bilirubin (grade 2), without definite evidence of AIH. However, liver biopsy revealed acute DILI with suspicious autoimmune features, including interface hepatitis, infiltration of inflammatory cells, and focal necrosis of hepatocytes. In addition, the revised Original Scores for AIH for pre- and post-treatment were 10 and 12, respectively. These two scores indicate that autoimmune features are probable. Although the mechanism of the corticosteroids is still unclear, it is presumed to be related to anti-inflammatory effects [5]. This is supported by our case, in which the patient improved after treatment of drug-induced, autoimmune-like hepatitis with corticosteroids.

For the imatinib rechallenge, a 25\% dose reduction was used after confirmation of normal blood levels of AST, ALT, and TB.

Drug rechallenge is associated with $13 \%$ mortality, and considerable comorbidity [13]. However, in clinical practice, the risk-benefit stratification for drug rechallenge is important and readministration may be undertaken carefully in the following cases: if continuous treatment, such as that needed for cancer, is required; there is no safer alternative treatment; if the benefit is judged to be greater than the risk; or if the patient consents after sufficient explanation of the risk of adverse event [13]. In our case, as all these conditions were satisfied, we re-administered imatinib. In addition, the dose reduction and dosage at the time of re-administration of the drug are not clearly defined, and individualization and treatment tailoring through close clinical follow-up is required.

In conclusion, the appropriate administration of oral steroids with prompt discontinuation of imatinib may be helpful for patients with imatinib-induced, autoimmune-like hepatitis.

\section{Conflicts of interest}

No potential conflicts of interest relevant to this article was reported.

\section{ORCID}

Min Kyu Kang, https:/ /orcid.org/0000-0002-1435-3312

Heon Ju Lee, https: / / orcid.org/0000-0002-9115-8131

Joon Hyuk Choi, https:/ / orcid.org/0000-0002-8638-0360

\section{References}

1. Pariente A, Etcharry F, Cales V, Laborde Y, Ferrari S, Biour M. Imatinib mesylate-induced acute hepatitis in a patient treated for gastrointestinal stromal tumour. Eur J Gastroenterol Hepatol 2006;18:785-7.

2. Tonyali O, Coskun U, Yildiz R, Karakan T, Demirci U, Akyurek $\mathrm{N}$, et al. Imatinib mesylate-induced acute liver failure in a patient with gastrointestinal stromal tumors. Med Oncol 2010;27:768-73.

3. Seidel C, Fenner M, Länger F, Bantel H, Ganser A, Grünwald $\mathrm{V}$. Imatinib-induced liver cirrhosis in a patient with advanced gastrointestinal stroma tumor (GIST). BMC Cancer 2012;12:186.

4. Yachoui R. Early onset imatinib mesylate-induced hepatotoxicity in a patient with gastrointestinal stromal tumors. Am J Ther 2014;21:e148-50.

5. Ferrero D, Pogliani EM, Rege-Cambrin G, Fava C, Mattioli G, Dellacasa $\mathrm{C}$, et al. Corticosteroids can reverse severe imatinibinduced hepatotoxicity. Haematologica 2006;91(6 Suppl): ECR27.

6. Al Sobhi E, Zahrani Z, Zevallos E, Zuraiki A. Imatinibinduced immune hepatitis: case report and literature review. Hematology 2007;12:49-53.

7. Guilhot F. Indications for imatinib mesylate therapy and clinical management. Oncologist 2004;9:271-81.

8. Sharma A, Houshyar R, Bhosale P, Choi JI, Gulati R, Lall C. Chemotherapy induced liver abnormalities: an imaging perspective. Clin Mol Hepatol 2014;20:317-26.

9. Joensuu H, Trent JC, Reichardt P. Practical management of tyrosine kinase inhibitor-associated side effects in GIST. Cancer Treat Rev 2011;37:75-88.

10. Almazroo OA, Miah MK, Venkataramanan R. Drug Metabolism in the Liver. Clin Liver Dis 2017;21:1-20.

11. Döring B, Petzinger E. Phase 0 and phase III transport in various organs: combined concept of phases in xenobiotic transport and metabolism. Drug Metab Rev 2014;46:261-82.

12. Willson TM, Kliewer SA. PXR, CAR and drug metabolism. Nat Rev Drug Discov 2002;1:259-66.

13. Hunt CM, Papay JI, Stanulovic V, Regev A. Drug rechallenge following drug-induced liver injury. Hepatology 2017;66:646-54.

14. Saif MW, Smith MH, Maloney A, Diasio RB. Imatinibinduced hyperbilirubinemia with UGT1A1 (*28) promoter polymorphism: first case series in patients with gastrointestinal stromal tumor. Ann Gastroenterol 2016;29:551-6. 